\title{
Implicaciones de la ley 1801 de 2016 en el proceso administrativo sancionatorio urbano en el Distrito de Barranquilla ${ }^{1}$.
}

\section{Implications of law 1801 of 2016 in the administrative process of sanctioning urban in the District of Barranquilla.}

\author{
Miguel Ángel Ferrer Jiménez ${ }^{2}$
}

Marlon Maury Vergara ${ }^{3}$

\section{RESUMEN}

\begin{abstract}
El presente artículo tiene por objeto analizar el cumplimiento de las necesidades de intervención estatal en materia de Derecho Urbano, en especial de la regular, vigilar y controlar del desarrollo urbanístico de las ciudades, es así como la funcionalidad de esta disciplina jurídica ha sido objeto de transiciones normativas que persiguen la optimización de los procesos cuya finalidad es mantener el orden urbanístico vigente. En virtud de lo anterior fue expedida una reciente reglamentación contenida en la Ley 1801 de 2016 Nuevo código de policía, que colocó en un escenario de invención jurídica a esta área del Derecho, específicamente al proceso administrativo sancionatorio urbano (PASU), puesto que es la primera vez que en nuestro país, un código de Policía está regulando el trámite que se debe desencadenar en la solución de controversias de tipo urbanístico.
\end{abstract}

\section{Palabras claves:}

Potestad sancionatoria del Estado, Proceso sancionatorio Urbano, infracciones urbanísticas, Derecho policivo, Derecho urbanístico.

\footnotetext{
1Artículo derivado de un trabajo de investigación desarrollado en el marco de la especialización en derecho administrativo de la Universidad Simón Bolívar de Barranquilla - disertaciones en torno a la entidades territoriales del Caribe Colombiano.

2 Abogado egresado de la Universidad del Atlántico, Especialista en derecho administrativo de la Universidad Simón Bolívar, ha realizado diplomados en Contratación Estatal (ESAP) E-mail:miguelferrer011@gmail.com

3 Abogado egresado de la Universidad Simón Bolívar, especialista en derecho administrativo de la Universidad Simón Bolívar

Recibido: 10 de Septiembre de 2018

Aprobado: 5 de Noviembre de 2018.
} 


\begin{abstract}
The purpose of this article is to analyze the fulfillment of the needs of state intervention in urban law matters, especially the regulation, monitoring and control of the urban development of cities, this is how the functionality of this legal discipline has been subject to normative transitions that pursue the optimization of processes whose purpose is to maintain the current urban order. In virtue of the above, a recent regulation contained in Law 1801 of 2016 was issued. New police code, which placed this area of law in a legal invention scenario, specifically the urban sanctioning administrative process, since it is the the first time that in our country, a police code is regulating the procedure that must be triggered in the solution of urban-type disputes
\end{abstract}

\title{
Keywords:
}

State sanctioning power, urban sanctioning process, urban infractions, police law, urban law

\section{Introducción}

El sector constructivo en cualquier economía representa un impacto de alto nivel, generando un crecimiento en la misma, es así como el Banco de la republica desde 1991 lo ha caracterizado como uno de los mecanismos reactivadores de la economía y por su aporte a la generación de empleo (Network, 1992), lo anterior nos conlleva a afirmar la influencia social que tiene el desarrollo urbanístico de una sociedad en la disminución del desempleo dentro de una sociedad.

En nuestro país desde hace unos años esta sección de la economía viene representado un crecimiento considerable y un dinamismo que repercute en la estabilidad de la economía nacional, para el 2007 la economía colombiana creció $7,5 \%$ con respecto al año anterior, cifra que se explica principalmente por la expansión de los sectores de la construcción (13,3\%), los servicios de transporte $(12,5 \%)$, la industria $(10,6 \%)$, y el comercio $(10,4 \%)$. Estos sectores, por lo tanto, han contribuido con un porcentaje cercano al $50 \%$ de la variación anual del PIB durante los últimos cuatro años (CAMACOL.2008;5) posicionándose de esta manera como la actividad que más contribuye a la economía nacional seguida del sector transporte, el distrito de Barranquilla específicamente se ha convertido en los últimos 5 años en un 
epicentro de desarrollo constructivo, lo cual genera la necesidad de ahondar en lo relacionado a un proceso que busca determinar la responsabilidad en el desarrollo de procesos de construcción.

Este aumento constructivo ha generado sin lugar a dudas un aumento de construcciones civiles que muchas veces pueden contrariar el régimen urbanístico vigente, siendo de vital importancia la determinación del proceso que se debe desencadenar frente a una presunción de infracción urbanística.

Ahora bien, ese dinamismo con el que se encuentra revestida la actividad constructiva debe marcar la pauta o la forma en como la potestad sancionatoria del estado actúa frente a las infracciones que se cometan durante el avance y desarrollo de las construcciones, debido a que el Estado no puede frenar el ritmo de desarrollo que representa este sector económico en el avance general de nuestro peculio nacional, ahora bien, ahondar sobre las incidencias que pueda tener la ley 1801 de 2016 en el proceso PASU marcara un impacto trascendental en los actores principales de aquella división de la economía, puesto que la reacción del estado con respecto las presuntas comisiones de infracciones urbanísticas frenara u optimizara esa tendencia de crecimiento de la edificación.

Por otro lado, lograr identificar claramente cuáles fueron las implicaciones de esta nueva normatividad policiva, sobre un tema que por muchos años fue ejecutado por autoridades administrativas y bajo otras ópticas procesales, representaría un gran aporte que ayudaría a clarificar el panorama jurídico-procesal en lo relativo a los procesos administrativos sancionatorios urbanos. 
Es así como el desarrollo de esta temática investigativa esta revestida de un alto nivel de pertinencia, toda vez que una economía cambiante y que influye en la calidad de vida de los habitantes no puede considerar menos importante el estudio de aquellas reglamentaciones jurídicas que inciden directamente en el sector que esta jalona la economía colombiana.

\section{Metodología}

El tipo de investigación utilizada fue la "documental", que consiste en una estrategia, donde se observa y reflexiona metódicamente sobre las realidades teóricas y empíricas, empleando distintos tipos de documentos donde se investigan, interpretan y presentan datos sobre un tema explícito de cualquier ciencia, utilizando métodos e instrumentos que tiene como propósito alcanzar resultados que serviría como base para la creación científica.

\section{Proceso sancionatorio urbano antes de la entrada en vigencia la ley 1801 de 2016 en el Distrito de Barranquilla}

El procedimiento administrativo sancionatorio en materia urbanística no ha tenido una regulación especial en cuanto a las etapas procesales a desarrollar frente a la comisión de infracciones urbanísticas, por lo cual, entes de que se expidiera la ley 1801 de 2016, se desarrollaban dichos procesos fundamentados en las reglamentaciones del procedimiento administrativo sancionatorio (PAS) contenido en la ley 1437 de 2011 (como norma general).

La ley 1437 de 2011 (CPACA) en su artículo 47 establece la aplicabilidad de tal proceso ante la ausencia de leyes especiales que regulen materias específicas, como es el caso que nos ocupa en el presente artículo. 
Es así como la acción urbanística podía iniciarse de oficio o a solicitud de cualquier persona, lo cual conlleva a que la oficina de control urbano y espacio público del distrito de Barranquilla antes de iniciar el PSA debía evacuar una indagación preliminar, con la finalidad de verificar la ocurrencia de la conducta y determinar si es constitutiva de infracción urbanística, si se determinaba la existencia de argumentos se podía dar inicio al proceso, dicha determinación se comunicaba al interesado. Es importante anotar que "aquella iniciación puede darse por cumplimiento de un deber legal, producto de la práctica administrativa de los organismos de inspección, vigilancia y control". (Laverde 2016, p.115).

Posteriormente la autoridad distrital formulaba cargos mediante acto administrativo en que se señalaba con absoluta precisión y claridad, lo hechos que lo originaron, las personas naturales o jurídicas objeto de la investigación, las disposiciones presuntamente violadas y las sanciones o medidas que serían procedentes. (Art 47, CPACA), este Acto administrativo se debía notificar personalmente al investigado y ante el cual no procedía ningún recurso.

En dicho pliego debía estar expresamente consagradas las acciones u omisiones que constituyen la infracción e individualizadas las normas urbanísticas que se estiman violadas o el daño causado, "este pliego marcara el derrotero de la actuación administrativa, al punto que debe existir plena congruencia entre el pliego y el acto sancionatorio (Cpaca, art. 49), so pena de nulidad de la actuación e incluso del acto definitivo." (Laverde, 2016, p.119).

Dentro de quince (15) días posteriores a la notificación al pliego de cargos, los investigados tenían la posibilidad de presentar descargos y solicitar o aportar las pruebas que pretendían valer dentro del procedimiento sancionatorio, pero si el 
investigado solicitaba pruebas inconducentes, impertinentes y superfluas eran rechazadas de manera motivada por el despacho.

Por su lado el artículo 48 del CPACA establece como etapa subsiguiente, el periodo probatorio el cual no podría ser superior a treinta (30) días, a excepción que sean tres o más los investigados, dicho plazo podría ser extendido hasta 60 días, una vez vencido este término, se daba traslado al investigado por diez (10) días para que presentara los alegatos que considerará pertinente.

Esta etapa se convierte en la oportunidad procesal más importante para el presunto infractor porque debe establecer su postura frente a los cargos que le pretenden acaecer, es por ello que el debate también debe centrarlo en las pruebas allegadas al expediente que deberá controvertirlas y también deberá solicitar las pruebas que considere pertinentes y conducentes, para que de esta manera obtenga el mejor provecho del proceso que se está desarrollando.

Una vez trascurrían treinta (30) posteriores a la presentación de dichos alegatos, la autoridad distrital tomaba la decisión por medio de un acto administrativo que debería contener cuatro (4) ítems señalados por el artículo 49 del CPACA.

1. La individualización de la persona natural o jurídica a sancionar.

2. El análisis de los hechos y pruebas con base en las cuales se impone la sanción.

3. Las normas infringidas con los hechos probados.

4. La decisión final de archivo o sanción y la correspondiente fundamentación 
Es preciso señalar que el CPACA en su artículo 50, establecía los criterios para graduar la sanción, al respecto rezaba:

1. Daño o peligro generado a los intereses jurídicos tutelados.

2. Beneficio económico obtenido por el infractor para sí o a favor de un tercero.

3. Reincidencia en la comisión de la infracción.

4. Resistencia, negativa u obstrucción a la acción investigadora o de supervisión.

5. Utilización de medios fraudulentos o utilización de persona interpuesta para ocultar la infracción u ocultar sus efectos.

6. Grado de prudencia y diligencia con que se hayan atendido los deberes o se hayan aplicado las normas legales pertinentes.

7. Renuencia o desacato en el cumplimiento de las órdenes impartidas por la autoridad competente.

8. Reconocimiento o aceptación expresa de la infracción antes del decreto de pruebas.

Al artículo 52 del Cpaca esboza que el termino de caducidad es de tres (3) años y se deberá contar a partir de haber sucedido el hecho u omisión generadora de la infracción, si se tratara de un hecho u omisión sucesivos, el término empezará a correr desde el último día en que se haya generado el hecho o la omisión, lo cual genera a las autoridades un tiempo amplio para que desarrollen el proceso sancionatorio, por otro lado, en lo referente a la decisión de los recursos el mismo artículo señala que dentro del término de caducidad, el acto administrativo que impone la sanción debe haber sido expedido y notificado, luego hace una diferenciación entre los actos sancionatorios de los actos que resuelven los recursos, los cuales deberán ser decididos, so pena de perdida de competencia, en un término de un (1) año contado a partir de su debida y oportuna interposición. 
Si los recursos no se deciden en el término fijado en esta disposición, se entenderán fallados a favor del recurrente, sin perjuicio de la responsabilidad patrimonial y disciplinaria que tal abstención genere para el funcionario encargada de resolver. Los recursos que proceden contra los actos administrativos en sede administrativa son los de reposición, apelación y queja, "la administración tiene un año para decidirlos, mas no un año para resolver cada uno de ellos". (Laverde, 2016, p.161)., reiteramos que este precepto legal constituye un panorama garantista en el desarrollo de los procesos sancionatorios que se desarrollan en sede administrativa, además, resulta importante mencionar que el que el artículo 52 del CPACA fue objeto de una demanda de constitucionalidad, y la Corte Constitucional en sentencia C-875 de 2011 estableció la hipótesis de silencio administrativo positivo que introduce el artículo 52 de la Ley 1437 de 2011 no se puede considerar contraria al derecho al debido proceso de la administración ni al orden social justo, pues es al Estado al que le corresponde definir la situación jurídica de los administrados. Cosa distinta es la responsabilidad civil y patrimonial del funcionario que omitió resolver en tiempo, asunto éste que el precepto acusado consagra expresamente. Por el contrario, su inclusión en el ordenamiento jurídico reconoce que la administración tiene un deber de respeto por los derechos fundamentales de los administrados. Por tanto, esta figura, salvo circunstancias excepcionales como la fuerza mayor o el caso fortuito que justifiquen la mora en la resolución del recurso, se ajusta al artículo 29 constitucional.

\section{Proceso sancionatorio urbano despues de la entrada en vigencia la ley 1801 de 2016 en el Distrito de Barranquilla}

La ley 1801 de 2016 (cnpc) paso a convertirse en una norma especial frente a la obligación de desplegar un PASU, de esta manera introdujo dentro de su parte sustancial los comportamientos que afectan la integridad urbanística y procesalmente estableció el proceso verbal abreviado como el apto al momento de imponer una sanción en ocasión a una infracción urbanística. 
Es importante señalar que, es la primera vez que en nuestro país un código de policía regula lo relativo a la actividad urbanística, convirtiéndolo a un proceso cuya naturaleza ahora es netamente policivo.

En la actualidad en el distrito de Barranquilla la competencia de iniciar los procesos sancionatorios urbanos en primera instancia está a cargo de los inspectores urbanos en virtud del decreto acordal no. 0932 de 2016 de diciembre 27 de 2016, donde se crearon veintiocho (28) inspecciones urbanas y en segunda instancia los recursos de apelación son resueltos por la secretaria de control urbano y espacio público como una autoridad especial en el ámbito urbanístico.

En cuanto al trámite del proceso verbal abreviado el artículo 223 de la citada ley, establece que se tramitaran por este proceso los comportamientos contrarios a la convivencia, de competencia de los Inspectores de Policía, los Alcaldes y las autoridades especiales de Policía, es así como establece las siguientes fases del proceso:

La iniciación de la acción de policía, podrá iniciarse de oficio o a petición de una persona que tenga interés o legitimidad activa en la conservación del orden urbanístico, no obstante, ante un comportamiento de flagrancia la autoridad de policía podrá iniciar la acción de manera inmediata por medio de audiencia pública en el lugar de los hechos.

Una vez el inspector urbano trascurridos cinco (5) días siguientes de conocida la querella o el comportamiento contrario a la convivencia, en caso de que no hubiera sido posible iniciar la audiencia de manera inmediata, se citará a audiencia pública al quejoso y al presunto infractor, mediante comunicación escrita, correo certificado, 
medio electrónico, medio de comunicación del que disponga, o por el medio más expedito o idóneo, donde se señale dicho comportamiento. (art 223 cnpc).

Posteriormente se celebrará una audiencia pública en el lugar de los hechos o en el despacho del inspector, donde se expondrán los argumentos de ambas partes por el termino de veinte (20) minutos, se extenderá invitación a conciliar entre el quejoso y el presunto infractor, de darse la conciliación automáticamente el proceso puede cesar, de no darse animo conciliatorio se decretaran la práctica de pruebas obedeciendo al postulado de pertinencia y conducencia, si en la necesidad de recolectar pruebas se necesitan conocimientos técnicos el inspector urbano requerirá a los técnicos especializados del sector central y descentralizado del nivel distrital, regularmente se solita el acompañamiento de los arquitectos de la oficina de control urbano y espacio público del distrito de Barranquilla.

Agotada la etapa probatoria, y el inspector urbano halla valorado detenidamente las pruebas obtenidas en el proceso, tomara una decisión por medio de una medida de policía o medida correctiva, exponiendo los argumentos que lo llevaron a decidir, dicha decisión quedara notificada en estrado.

En cuanto a los recursos de ley, el interesado podrá imponer el de reposición (sustentado en audiencia) ante el inspector urbano y el de apelación (deberá sustentarse trascurridos tres días máximo) ante el secretario de control urbano y espacio público del distrito de Barranquilla.

Sobre la aplicación de medidas correctivas en asuntos relativos a infracciones urbanísticas, el recurso de apelación se concederá en el efecto suspensivo, una vez quede ejecutoriada la decisión que contenga una orden de Policía o una medida correctiva, esta se cumplirá en un término máximo de cinco (5) días. 


\section{Conclusiones}

El desarrollo del proceso sancionatorio administrativo como norma general que reglamentaba el proceso sancionatorio urbano, ante la inexistencia de una norma especial, podría tardar entre 80 y 120 días, lo cual generaba en la administración publica una falta de eficiencia al momento de la conservación del orden urbanístico.

El proceso sancionatorio administrativo urbano bajo las directrices de la ley 1437 de 2011 se desarrollaba bajo un sistema escritural, lo cual no iba en coherencia con las tendencias de oralidad de las ciencias jurídicas contemporáneas. El nuevo proceso sancionatorio urbano, contenido en la ley 1801 está diseñado para evacuarse en el menor tiempo posible, en un aproximado de 15 a 30 días, generando eficiencia y una mejor percepción de la ciudadanía frente a las actuaciones de las autoridades del distrito de Barranquilla.

EI PSAU bajo los postulados de la ley 1801 de 2016 reviste una naturaleza policiva, situación que podría generar controversias jurídicas al momento de identificar la procedibilidad de un medio de control judicial (Pérez Vázquez, 2015) ante la jurisdicción de lo contencioso administrativo. 


\section{Referencias.}

Alcaldía Distrital de Barranquilla.(2016) decreto acordal no. 0932 de 2016. Gaceta Distrital (428), P. 4-5.

Congreso de la república de Colombia. (18 de enero 2011). Código de procedimiento administrativo y de lo contencioso administrativo.Ley 1437 de 2011

Congreso de la república. (29 de julio 2016) Código nacional de policía y convivencia. ley 1801 de 2016

Corte constitucional. (22 de noviembre de 2011). C-875-2011. MP: Jorge Ignacio Pretelt Chaljub

Departamento de Estudios Económicos de CAMACOL. 2008. El sector de la construcción en Colombia: hechos estilizados y principales determinantes del nivel de actividad. Recuperado de: https://camacol.co/sites/default/files/secciones_internas/EE_Inv2008111910114 1_0.pdf

Laverde, J. (2016). Manual de procedimiento Administrativo Sancionatorio. Bogotá, Colombia: LEGIS.

Miguel Marienhoff (2002). Tratado de Derecho Administrativo. Recuperado de: http://escuelasuperior.com.ar/instituto/wp-content/uploads/2015/07/Tratado-deDerecho-Administrativo-Miguel-Marienhoff-Tomo-V.pdf

Network. (1992) La importancia del sector de la construcción en materia económica. Banco de la Republica 1992. Recuperado de: http://la.network/la-importanciadel-sector-de-la-construccion-en-materia-economica/ 
Ferrer-Jiménez, Miguel Ángel \& Maury-Vergara, Marlon. 64

Pérez Vásquez, R. (2015). La decisión judicial. Erg@omnes, 7(1), 30-55. https://doi.org/https://doi.org/10.22519/22157379.742 